\title{
The Relationship between Mental Health and Physical Exercise among Male College Students
}

\author{
Xinhai Yang* \\ Zhejiang University of Water Resources and Electric Power \\ Hangzhou, China \\ yxh7612@vip.qq.com
}

\begin{abstract}
To compare the mental health condition of male college students with that of those who participate sports team, and discuss how to adopt better physical exercise method to improve the mental health of college students. The 480 male college students were tested and surveyed by using Symptom Check List90( SCL-90)table and other means. The results demonstrate (1) The mentality of the male college students who participate sports team is obviously better than normal male college students. (2) In sports team, the mentality of the male college students who take part in collective items is better than that of those who take part in individual items. Therefore, long time and multiform physical exercise are beneficial to the development of students' mental health.
\end{abstract}

Keywords-Different levels; College students ; sports team; mental health

\section{INTRODUCTION}

Recently, depression, loneliness, stress hopelessness, suicide and other mental health issues of college students have attracted the attention from all sectors of society. As to college students who have high intelligence quotient, it is a competition of mental quality rather than a competition of intelligence quotient. Quality-oriented education of colleges and universities still faces vital issues such as how to increase the mental quality of college students, how to strengthen their ability to adapt to challenges so as to be more suitable to the changeable social environment.

Along with the constant development of society, people have paid more attention to physical activities and mental health. Studies suggest that exercise and physical activity are associated with better quality of life and health outcomes. Assessment and promotion of exercise and physical activity may be beneficial in achieving desired benefits across several populations (1). It is recommended that participation in sport is advocated as a form of leisure-time physical activity for adults which can produce a range of health benefits (2). In addition, taking sports activities also facilitated learning and improving social skills (3), which will bring positive impact on their mental health. It is vital and urgent to increase the level of mental health through participating in physical activities. This paper aims to compare mental health conditions of male college students who join the sports team with that of common male college students. Then it will analyze and discuss the relationship between physical exercise and mental health. Furthermore, it will also explore methods to increase the level of mental health for male college students through physical exercise so as to provide theoretical bases for physical education to implement mental health education.

\section{MATERIALS AND METHODS}

There are 200 male students in sports team (Football Team, Basketball Team, Volleyball Team, Track and Field Team, Ping-Pong Team, Tennis Team, Aerobics Team) of Zhejiang University of Water Resources and Electric Power. 300 fulltime male students from freshmen to junior are randomly chosen (their average age is 20.5 years old).

There are 500 copies of questionnaire issued. Among them, there are 480 copies withdrawn which are valid (the rate of validity is $96 \%$ ). SCL -90 table is applied to investigate the mental health condition of male college students. The table is consisted of 9 factors that can reflect mental illness including somatization, compulsion, sensitive of interpersonal relationship, depression, anxiety, hostility, terror, bigotry and psychoticism. Students' mental health is evaluated from level 1 to level 5. All data is calculated by SPSS19.0 software.

\section{RESULTS}

A. Comparison of Mental Health between Male College Students in Sports Team and Common Male College Students

Through comparing the nine factors of SCL -90 of male college students in sports team with these of common male college students (table 1 ), the result of t-test shows that the scores of these nine factors obtained by male college students in sports team are obviously lower than scores of common male college students, which implies that mental health condition of male college students in sports team are much better than that of common male college students. Moreover, the scores of our male college students in sports team are generally lower than the domestic average level.

As to the factors of compulsion, anxiety and terror, the scores of our common male college students are also lower than the domestic average level. The reason is that most of our students are from Zhejiang whose economic level is relatively higher than that of other regions. Most families are in a favorable economic condition and suffer less stress. Secondly, Zhejiang has a higher economic level and can provide more jobs that students suffer less employment pressure. 
TABLE 1. COMPARISON OF MENTAL HEALTH BETWEEN MALE COLLEGE STUDENTS IN SPORTS TEAM AND COMMON MALE COLLEGE STUDENTS $(\bar{X} \pm S)$

\begin{tabular}{lccc}
\hline \multicolumn{1}{c}{ Factors } & $\begin{array}{c}\text { Domestic } \\
\text { Average Level }\end{array}$ & $\begin{array}{c}\text { Students in } \\
\text { Sports Team } \\
(\mathbf{n = 1 9 5 )}\end{array}$ & $\begin{array}{c}\text { Common } \\
\text { Students } \\
(\mathbf{n}=\mathbf{2 8 5})\end{array}$ \\
\hline somatization & $1.57 \pm 0.55$ & $1.41 \pm 0.37$ & $1.59 \pm 0.56^{* *}$ \\
compulsion & $2.03 \pm 0.66$ & $1.78 \pm 0.49$ & $1.96 \pm 0.59^{* *}$ \\
Sensitive of & $1.92 \pm 0.65$ & $1.74 \pm 0.48$ & $1.91 \pm 0.59^{* *}$ \\
interpersonal & $1.91 \pm 0.64$ & $1.53 \pm 0.50$ & $1.89 \pm 0.69^{* *}$ \\
relationship & $1.68 \pm 0.58$ & $1.41 \pm 0.47$ & $1.59 \pm 0.62^{* *}$ \\
depression & $1.73 \pm 0.69$ & $1.51 \pm 0.51$ & $1.73 \pm 0.66^{* *}$ \\
anxiety & $1.54 \pm 0.56$ & $1.29 \pm 0.38$ & $1.46 \pm 0.52^{* *}$ \\
hostility & $1.84 \pm 0.63$ & $1.56 \pm 0.47$ & $1.81 \pm 0.59^{* *}$ \\
terror & $1.61 \pm 0.58$ & $1.47 \pm 0.42$ & $1.59 \pm 0.50^{* *}$ \\
bigotry & & & \\
\hline psychoticism & & & \\
\hline
\end{tabular}

Note: $\mathrm{P}<0.05^{*} \quad \mathrm{P}<0.01 * *$

B. Comparison of Mental Health between Male College Students Who Participate in Group Events and Male College Students Who Participate in Individual Events

Through comparing the nine factors of SCL -90 of male college students who participate in group events and male college students who participate in individual events (table 2), result of t-test shows that apart from factors of somatization and psychoticism ( $>>0.05)$, the scores of the rest seven factors of male college students who participate in group events are obviously lower than the scores of male college students who participate in individual events. Therefore, it can be found out that male college students who participate in group events have a higher level of mental health. In addition, the scores of male college students who participate in group events and male college students who participate in individual events are all lower than domestic average level.
TABLE 2. COMPARISON OF MENTAL HEALTH OF MALE COLLEGE STUDENTS WHO PARTICIPATE IN DIFFERENT $\operatorname{ACTIVITIE}(\bar{X} \pm \mathrm{s})$

\begin{tabular}{lccc}
\hline \multicolumn{1}{c}{ Factors } & $\begin{array}{c}\text { Domestic } \\
\text { Average Level }\end{array}$ & $\begin{array}{c}\text { Students in } \\
\text { Sports Team } \\
(\mathbf{n = 1 0 2})\end{array}$ & $\begin{array}{c}\text { Common } \\
\text { Students (n=93) }\end{array}$ \\
\hline somatization & $1.57 \pm 0.55$ & $1.40 \pm 0.49$ & $1.43 \pm 0.48$ \\
compulsion & $2.03 \pm 0.66$ & $1.70 \pm 0.53$ & $1.87 \pm 0.59^{* *}$ \\
$\begin{array}{l}\text { sensitive } \\
\text { interpersonal }\end{array}$ & $1.92 \pm 0.65$ & $1.69 \pm 0.55$ & $1.80 \pm 0.55^{* *}$ \\
relationship & $1.91 \pm 0.64$ & $1.48 \pm 0.57$ & $1.58 \pm 0.61^{*}$ \\
depression & $1.68 \pm 0.58$ & $1.36 \pm 0.48$ & $1.46 \pm 0.59^{*}$ \\
anxiety & $1.73 \pm 0.69$ & $1.46 \pm 0.56$ & $1.57 \pm 0.60^{*}$ \\
hostility & $1.54 \pm 0.56$ & $1.24 \pm 0.42$ & $1.35 \pm 0.49^{* *}$ \\
terror & $1.84 \pm 0.63$ & $1.48 \pm 0.54$ & $1.64 \pm 0.48^{* *}$ \\
bigotry & $1.61 \pm 0.58$ & $1.46 \pm 0.44$ & $1.49 \pm 0.46$ \\
\hline psychoticism & & & \\
\hline
\end{tabular}

Note: $\mathrm{P}<0.05^{*} \quad \mathrm{P}<0.01 * *$

\section{DISCUSSION}

\section{A. Comparison of Mental Health between Male College} Students in Sports Team and Common Male College Students

Through comparing the nine factors of SCL -90 of male college students in sports team and common male college students, it can be seen that mental health of male college students in sports team is much better than that of common male college students. Apart from PE class, our male college students in sports team exercise at least 3 times every week and the time of every exercise is over 90 minutes. However, the average time of exercise of common male college students is less than 30 minutes besides PE class. It can be seen that physical exercise is important to increase the level of mental health for college students.

Research suggests that physical exercise can increase the content of Leu-Enkephalin and also help students to vent bad emotions so as to balance mental status and promote mental health. These common male college students do not have the same physical training conditions to students in sports team. PE class of each week also cannot satisfy students to have enough physical exercise. Therefore, how to organize common students to participate in physical exercise as much as possible becomes the urgent issue that faced by education department of schools.

\section{B. Effect on Mental Health by Participating in Different Physical Events}

Through comparing the nine factors of SCL -90 of male college students who participate in group events and male college students who participate in individual events, it can be seen that mental health of male college students who participate in group events is much better than that of male college students who participate in individual events. If students often participate in physical activities, a relaxed and harmonious atmosphere will be created among students. More importantly, students can also learn to cooperate and 
communicate with each other when having physical activities which can definitely strengthen their concept of collectivism and team cohesiveness so as to realize the goal of mutual understanding and cooperation. Students who usually participate in group events may have more chances to communicate and cooperate with their partners which will be beneficial to mental health.

As common full-time students, they should enrich their physical exercise hobbies and actively participate in various physical activities so as to get more chances to communicate with others and improve mental health.

Mental disorders are as prevalent among college students as same-aged non-students, and these disorders appear to be increasing in number and severity (4).Mental health education is a representation of quality-oriented education. Mental health education of colleges and universities should put students' healthy development first and adhere to the synergetic development of all physical and mental factors so as to create a healthy mental status for students through various channels.

We have achieved a successful result at the aspect of physical exercise of sports team. However, administrative department of sports should not only emphasize on the physical exercise of sports team, but also pay attention to extracurricular exercise of common students by referring to the successful experience obtained from sports team. Various physical activities which are similar to the exercise of sports team should be carried out and more sports clubs should be established. Furthermore, more gymnasiums should be open to common students so as to arouse their interest towards sports and attract more students to participate in activities. In this way, students' mental health will be improved through a long-term and various physical activities. Participants engaging in regular physical activity will display more desirable health outcomes across a variety of physical conditions.

Although physical activity takes many forms, most research designed to enhance motivation for and adherence to physical activity focuses on exercise behavior and ignores sport participation. Studies suggest that motives for sport participation are more desirable than those for exercise and may facilitate improved adherence to physical activity recommendations. Therefore, more research will need to be conducted to address the important motivation and adherence issues(5). In the future, our studies will focus on the relationship between sports participation and health in college students.

\section{ACKNOWLEDGMENTS}

I would like to thank Di Jin and Xiaoyuan Jia for their advice about this paper.

\section{REFERENCES}

[1] Penedo FJ and Dahn JR, "Exercise and Well-being: a Review of Mental and Physical Health Benefits Associated with Physical Activity," Curr Opin Psychiatry, Vol. 18, Mar. 2005, pp.189-193.

[2] Eime RM1, Young JA, Harvey JT, Charity MJ and Payne WR, “A Systematic Review ofThe Psychological and Social Benefits of Participation in Sport for Aults: informing development of a conceptual model of health through sport,” Int J Behav Nutr Phys Act., Dec 2013. doi: 10.1186/1479-5868-10-135.
[3] Lu Lv and Kazushi Takami, “The Relationship between Social Skills and Sports Activities among Chinese College Students,” Psychology , Vol. 6, Mar 2015, pp.393-399.

[4] Justin Hunt and Daniel Eisenberg, "Mental Health Problems and HelpSeeking Behavior Among College Students,” Journal of Adolescent Health, Vol. 46, Jan. 2010, pp.3-10.

[5] Marcus Kilpatrick, Edward Hebert and John Bartholomew, "College students' motivation for physical activity: differentiating men's and women's motives for sport participation and exercise,” Journal of American College Health,Vol54, Aug 2010, pp87-94. 